\title{
Emvolio - A battery operated portable refrigerator preserves \\ biochemical and haematological integrity of biological
}

\section{samples in preclinical studies [version 1; peer review: 1}

\section{approved with reservations]}

\author{
Swastika Maity1', Jaya Aakriti1, Suman Manandhar (D1), Sharad B Anchan², \\ Ashlesh Bhat², Mayur U Shetty², Yogendra Nayak (iD)1 \\ ${ }^{1}$ Department of Pharmacology, Manipal College of Pharmaceutical Sciences, Manipal Academy of Higher Education, Manipal, \\ Karnataka, 576104, India \\ 2Blackfrog Technologies Private Limited, Manipal, Karnataka, 576104, India
}

\author{
V1 First published: 24 Feb 2022, 11:223 \\ https://doi.org/10.12688/f1000research.109134.1 \\ Latest published: 19 Jan 2023, 11:223 \\ https://doi.org/10.12688/f1000research.109134.2
}

\section{Abstract}

Background: Emvolio is a non-medical device, indigenously developed portable refrigeration for maintaining the internal temperature $2-8^{\circ} \mathrm{C}$. The Indian Patent Office has granted patent for applications such as preservation and transport of medicines, vaccines, food, beverages, dairy etc. Further, use of Emvolio can be utilized in transport and store biologicals to preserve their biochemical and cellular integrity. The objective of this study was to evaluate the biochemical and haematological integrity of biological samples such as rat blood, serum and liver.

Methods: The steady temperature was maintained inside the Emvolio, and it was compared to that of thermocol and polypropylene boxes aided with frozen gel packs. The blood and liver samples were isolated from Wistar rats and kept in Emvolio, thermocol and polypropylene boxes for $10 \mathrm{hrs}$, and the temperature was monitored. The blood parameters, namely red blood cells (RBC), white blood cells (WBC), platelets, haematocrit, haemoglobin, mean corpuscular volume (MCV), mean corpuscular haemoglobin concentration (MCHC) and red cell distribution width (RDW), serum parameters like alanine transaminase, alkaline phosphatase, total protein, albumin, creatine kinase, blood urea nitrogen and liver parameters like superoxide dismutase (SOD), glutathione (GSH), catalase were estimated and compared.

Results: Emvolio maintained a constant inner temperature range of $2-8^{\circ} \mathrm{C}$, whereas a significant temperature variation was seen in thermocol and polypropylene boxes. There was no significant deviation in the parameters tested when samples were kept in

\section{Open Peer Review}

Approval Status ?

1

version 2

(revision)

19 Jan 2023

version 1

24 Feb 2022

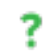

view

1. Ciro Aprea, University of Salerno, Salerno,

Italy

Any reports and responses or comments on the article can be found at the end of the article. 
Emvolio for six hours compared to the zero hour readings. In contrast, there was a significant deviation among the parameters for the samples kept in thermocol and polypropylene boxes for six hours compared to zero hour parameters.

Conclusions: Emvolio maintained constant temperature and

preserved the biological integrity of rat blood, serum and liver. Thus, Emvolio can be efficiently used as a biological sample carrier, especially in preclinical studies.

Keywords

Emvolio, portable refrigerator, biologicals, storage, transportation

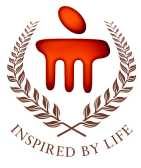

This article is included in the Manipal Academy

of Higher Education gateway.

\section{Corresponding author: Yogendra Nayak (yogendra.nayak@manipal.edu)}

Author roles: Maity S: Conceptualization, Data Curation, Formal Analysis, Investigation, Methodology, Validation, Writing - Original Draft Preparation; Aakriti J: Formal Analysis, Investigation, Methodology, Validation; Manandhar S: Formal Analysis, Investigation, Methodology, Validation; Anchan SB: Resources, Visualization; Bhat A: Resources; Shetty MU: Resources; Nayak Y: Conceptualization, Data Curation, Formal Analysis, Methodology, Writing - Original Draft Preparation

Competing interests: Authors Sharad B Anchan, Ashlesh Bhat, Mayur U Shetty, have developed and patented the product Emvolio and they have started a start-up Blackfrog Technologies Private Limited, Manipal, Karnataka, India, Pin - 576104. However, the current work is taken care independently at the department of Pharmacology, Manipal College of Pharmaceutical Sciences, MAHE Manipal.

Grant information: The author(s) declared that no grants were involved in supporting this work.

Copyright: @ 2022 Maity S et al. This is an open access article distributed under the terms of the Creative Commons Attribution License, which permits unrestricted use, distribution, and reproduction in any medium, provided the original work is properly cited.

How to cite this article: Maity S, Aakriti J, Manandhar S et al. Emvolio - A battery operated portable refrigerator preserves biochemical and haematological integrity of biological samples in preclinical studies [version 1; peer review: 1 approved with reservations] F1000Research 2022, 11:223 https://doi.org/10.12688/f1000research.109134.1

First published: 24 Feb 2022, 11:223 https://doi.org/10.12688/f1000research.109134.1 


\section{Introduction}

Collection, storage and transportation of biologicals has become the chief investment by industry, academia and public research organizations ${ }^{1}$. Due to the highly sensitive nature of the biologicals to environmental conditions like heat and moisture, samples such as blood, serum, saliva, tissue, and organ samples are utilized in the hospital and medical industry to diagnose and experiment for preclinical or clinical studies ${ }^{2,3}$. The international agency for research on cancer (IARC) describe the storage conditions for different biologicals ${ }^{4}$. The guidelines for the transportation and preservation of biological products are as per the National Institute of Health (NIH), International Society for Biological and Environmental Repositories (ISBER), Center for Biologics Evaluation and Research (CBER), and Food and Drug Administration (FDA). The biological sample collection, storage, transportation and preservation includes multidisciplinary collaboration among experts in drug discovery, engineering, and other health professionals. The stocks for the use of biologicals in the health care sector is rising every day, especially in pharmaceutical sectors ${ }^{6}$. This condition has made the health care system rely on technology to ensure the maintenance of temperature. Over the past ten years, dependence on technology has increased for cold chain management ${ }^{7}$. Especially during the COVID-19 pandemic, the importance of cold-chain management became more prominent ${ }^{8}$. Generally, $2-8^{\circ} \mathrm{C}$ temperature is maintained by freezing, whereas for some products freezing should not be done. As per WHO guidelines, biologicals must not be frozen and should be transported and stored at $36-46^{\circ} \mathrm{F}$ $\left(2-8^{\circ} \mathrm{C}\right)$. Particular reference to vaccines, ensuring compliance with temperature in all stages of storage and transport is a must. Researchers are using thermocol based units, polypropylene units, or insulated plastic containers extensively. The thermocol box and polypropylene chillers are the cheapest alternatives that researchers and hospitals can use to transfer biological and blood samples. But due to lack of adequate temperature control, unavailability of information of the sample inside without opening the box itself results in loss of effectiveness in transportation. Hence, technological advancement is required for maintaining the cold chain requirement of biologicals at their optimum level.

Emvolio is a portable active cooling device developed by Blackfrog technologies Pvt Ltd, Manipal, India, for the transportation, delivery and storage of biologicals, especially medicines, vaccines, food, beverages, dairy etc. However, this can also be used to preserve and transport serum, blood and culture samples that are required to be kept strictly between $2-8^{\circ} \mathrm{C}$ (Figure 1). A 20 MAh rechargeable battery powers this portable device. This battery is roughly equivalent to a commercial cell phone battery. Emvolio device gives $100 \%$ accountability to ensure temperature and aims to replace the standard thermocol based carrier or polypropylene-based containers. This device can maintain $2-8^{\circ} \mathrm{C}$ for $10 \mathrm{hrs}$, have $1.5 \mathrm{~L}$ of capacity and weighs $5 \mathrm{~kg}$. This technology supports rapid cooling and quick stabilization of temperature. It has $96 \%$ faster cooling capacity than ice-based technology in all weather conditions, and the device was tested by the company with operational capability at a temperature between $-10^{\circ} \mathrm{C}$ to $43^{\circ} \mathrm{C}$. Emvolio device works on a thermoelectric refrigeration

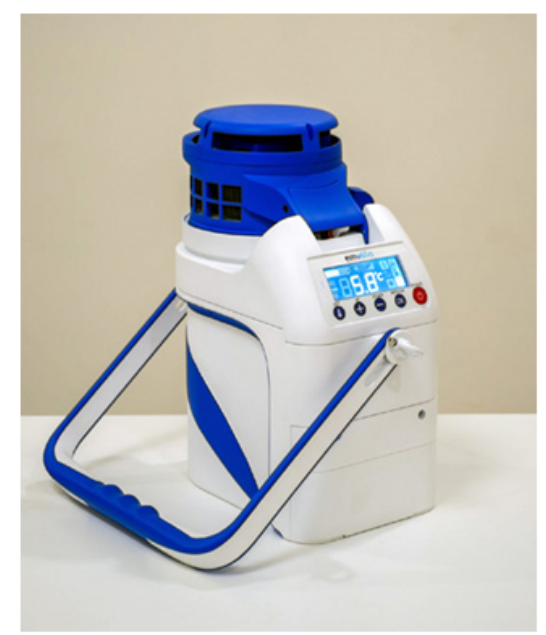

Figure 1. Emvolio portable refrigerator for transportation of biologicals/biological sample (product of Blackfrog technology Pvt Ltd, Manipal, India).

principle and has an embedded temperature monitoring device controller, which helps in the dynamic temperature control feedback mechanism (Figure 2). Emvolio has been certified by the Directorate General of Health Services, Ministry of Health and Family Welfare and National Regulatory Authority (NRA), India, following the Central Drugs Standard Control Organisation (CDSCO) guidelines as a non-medical device. The manufacturing company Blackfrog Technologies, Pvt. Ltd., also owns a patent for the same (Indian patent no 201941013056).

The current objective was to estimate whether Emvolio can maintain steady temperature control of $2-8^{\circ} \mathrm{C}$ in comparison with thermocol, polypropylene-based boxes supported by ice packs and room temperature conditions. The objective was also to identify deviation in blood, serum and organ biochemical parameters stored in Emvolio, thermocol based boxes, polypropylene-based boxes supported by ice packs and room temperature.

\section{Methods}

Preparation of cooling devices

Emvolio was fully charged before the investigation. The gel pads were kept in a deep freezer for $24 \mathrm{hrs}$ before the experiment. A temperature monitoring device, model RC-5 by Elitech, which follows the gold standard for monitoring thermal conductivity, was used. All four groups had their separate RC-5, Elitech devices for monitoring the temperature fluctuation. All three boxes were kept at room temperature. The RC-5, Elitech device was kept in Emvolio once it reached the temperature of $4^{\circ} \mathrm{C}$ as per the protocols set by the manufacturer. The RC-5, Elitech device was kept in the thermocol and polypropylene boxes $1 \mathrm{hr}$ after keeping the gel pads as per the guidelines of cold chain management. The study was conducted forenoon 8.30-9 AM to 11.20-12 AM daily for seven days. Emvolio was charged after $9 \mathrm{hrs}$, and the gel pads were changed at $10 \mathrm{hrs}$. The data was collected each day after the experiment and analyzed. 


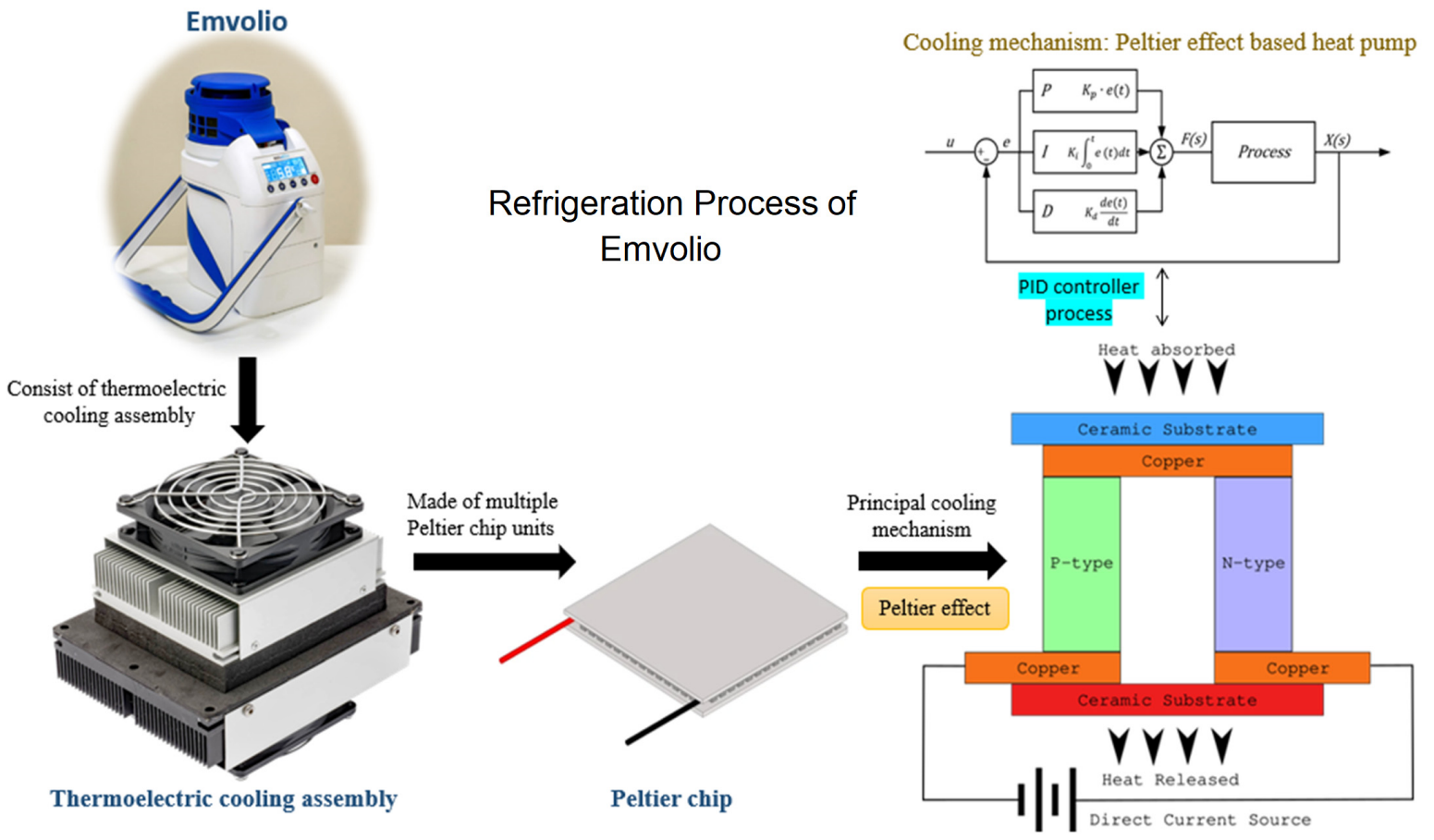

Figure 2. Thermodynamic mechanism used in Emvolio for its refrigeration technique of biological samples. The device has a cooling assembly made up of Peltier chips units. The cross-section of a simple Peltier effect based heat pump is presented in the figure. The blue side is the principal cooling mechanism known as the cold side, and the red as the hot side. Most Peltier chips have multiples of the structure in the figure in parallel to having higher power heat pumps. The device is linked with proportional-integral-derivative (PID) controller process to get accurate setpoint control and fast reaction to disturbance.

Emvolio and the other alternatives were validated by the use of Q-tag ${ }^{\circledR}$. The Q-tag ${ }^{\circledR}$ is a range of WHO Performance Quality Safety (PQS) certified wireless temperature-sensors manufactured by Berlinger, a Swiss temperature monitoring solution company. Q-tag ${ }^{\circledR}$ is the gold standard for the cold chain monitoring system for biologicals and vaccines as per WHO.

\section{Procuring the rats and sample collection}

Institutional animal ethics committee (IAEC) approval

All the applicable international, national and institutional guidelines for the care and use of animals were applied in the experiments. The experimental work was approved by IAEC (\#IAEC/KMC/81/2019) of Manipal Academy of Higher Education (MAHE), and the experiments were carried out at the Central Animal Research Facility, Manipal, Karnataka, India (CPCSEA Reg no. 94/Po/ReBi/S/1999/CPCSEA). Rats were procured and acclimatized for seven days in 12 hrs light and dark cycle. Rats were fed with a standard pellet diet and water ad libitum. Each cage made up of polypropylene was used to cage two rats in each. The study was conducted as per the ARRIVE guidelines 2.0 using the ARRIVE Essential 10 checklist for pre-clinical animal studies ${ }^{9}$ and all efforts were made to ameliorate any suffering of animals during the experiments.

\section{Experimental design}

Three months old female Wistar rats weighing 150-180 g were used for the study. The rats were sacrificed after anaesthetising with intraperitoneal ketamine and xylazine solution (9:1) solution. The blood was collected by cardiac puncture in small test tubes coated with anticoagulant $10 \%$ EDTA (Cat. No.: 10378-23-1; Sigma-Aldrich). EDTA 10\% solution was made using Milli-Q water. Part of the blood was also collected in the Eppendorf tubes, and the serum was isolated after coagulation. The livers were perfused and isolated from the rat body. The samples of blood with anticoagulant, serum and liver were stored in a different container as per the following grouping. Each group contained $n=6$ female Wistar rats.

\section{Group I: Emvolio (instrument for consideration)}

Group II: Thermocol box padded with gel pads (common method for biological transfer in hospital and labs)

Group III: Polypropylene box with gel pads (common method for biological transfer in hospital and labs)

Group IV: Room temperature (control group)

The blood, serum and liver from each group of rats were stored in Emvolio, thermocol box, polypropylene box and room temperature. The storage at room temperature was kept as a control group for comparison (Figure 3). The biochemical data from the groups thermocol box, polypropylene box, room temperature and Emvolio groups were compared.

Evaluation of haematological parameters

The RC-5, Elitech device was kept in Emvolio once it reached the temperature of $4^{\circ} \mathrm{C}$ as per the protocols set by the 

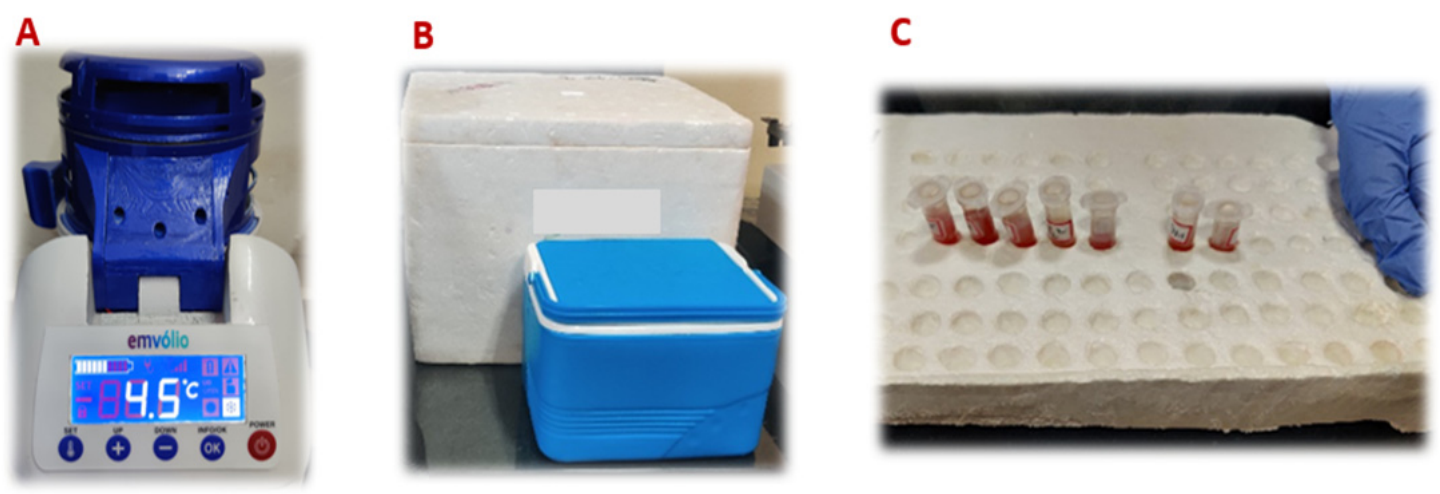

Figure 3. Containers of four groups, namely A: Emvolio; B: Thermocol box and Polypropylene box; C: Room temperature for the study loaded with biologicals.

manufacturer Blackfrog technologies, Manipal. The RC-5, Elitech device was placed in the thermocol and polypropylene boxes to monitor the temperature fluctuations. Blood was collected in a test tube with $10 \%$ EDTA solution to avoid coagulation of blood ${ }^{10}$ and was kept in the respective group containers. The blood samples were tested at a time interval of $3 \mathrm{hr}$ intervals, $0 \mathrm{hr}, 3 \mathrm{hr}$ and $6 \mathrm{hrs}$, using the Veterinary blood cell counter (PCE-210VET, ERMA Inc., Tokyo, Japan). The blood samples were tested for total red blood cells (RBC), white blood cells (WBC), platelet, haemoglobin ( $\mathrm{Hb}$ ), haematocrit, mean corpuscular volume (MCV), mean corpuscular haemoglobin concentration (MCHC) and red cell distribution width $(\mathrm{RDW})^{11}$. The temperature of each box was noted after the biological sample analysis was completed.

\section{Evaluation of serum and organ parameters}

The serum and organs were preserved in their respective labelled containers for further investigation. The serum enzymes were analyzed using kits from Agappe, Sigma, and Elabsciences in the Agappe UV auto-analyser. The following kits were procured to conduct the study: blood urea nitrogen kit (Cat. No. 11610002), alanine transaminase (ALT) (Cat. No: 11409005; 11409006), alkaline phosphatase (ALP) (Cat. No: 11401010), lactate dehydrogenase (LDH) (Cat. No: 12011015), serum creatinine (creatinine) (Cat. No: 11420002), albumin (ALB) (Cat. No: 12011002) and total protein (TP). Around $1.5 \mathrm{~mL}$ of blood was collected for each sample of individual groups and was centrifuged at $8,000 \mathrm{rpm}$ for $10 \mathrm{~min}$ to collect the serum sample. The parameters selected for the serum analysis were reported to be highly temperature-sensitive standardized studies; so, selective parameters were analyzed to find out the temperature variation effect on the serum sample of each group $^{12}$.

The liver sample was homogenized in $10 \%$ ice-cold $\mathrm{KCl}$ $(150 \mathrm{mM})$ solution (Merck, Cat. No: 60142) ${ }^{13}$. The homogenate was then centrifuged at $8,000 \mathrm{rpm}$ for $10 \mathrm{~min}$, and the supernatant was separated and kept in their respective labelled container (Emvolio, thermocol box, polypropylene box and room temperature). The samples for the group room temperature were kept on a centrifuge tube stand. Organ parameters were performed by homogenization of the liver sample and estivation of its antioxidant property. Superoxide dismutase (SOD), glutathione (GSH) analysis was done using the fluorescent plate reader (FLx800, Biotek), and catalase were estimated using UV spectrophotometer (UV-1650pc TBS instrument). This experiment was carried out throughout 12 hrs. Each sample for both serum and organ analysis was performed over a time interval of $3 \mathrm{hrs}$ to estimate the effect of temperature on the biologicals. Therefore, the samples were analyzed at $0 \mathrm{hr}$, $3 \mathrm{hr}$ and $6 \mathrm{hrs}$ for their biochemical estimation.

\section{Statistical analysis}

Statistical analysis was done using two-way ANOVA in GraphPad Prism version $8.0 \mathrm{p}<0.05$ was considered a significant difference for the comparison of all the parameters. The calculations which were done in GraphPad Prism can be done in Microsoft Excel by adding the free extension Analysis ToolPak by Microsoft®.

\section{Results}

Effect of temperature fluctuation during the storage

The temperature recording done for $10 \mathrm{hrs}$ over seven days in different cooling systems is represented in Figure 4. Constant maintenance of temperature within the range of $4-8^{\circ} \mathrm{C}$ was observed in the Emvolio cooling system kept at normal room temperature $\left(30^{\circ} \mathrm{C}\right)$. Both gel-based cooling systems in the thermocol box and polypropylene box could not maintain the temperature in the $4-8^{\circ} \mathrm{C}$ range, and temperature fluctuations above $8^{\circ} \mathrm{C}$ was observed during the $10 \mathrm{hrs}$ observation period. After the duration of the $4 \mathrm{hrs}$, in both polypropylene and thermocol boxes, an increase in the temperature from $8^{\circ} \mathrm{C}$ to $10^{\circ} \mathrm{C}$ was noticed. In contrast, the Emvolio cooling system maintained constant temperature $\left(4-8^{\circ} \mathrm{C}\right)$ without significant deviations throughout the study duration.

\section{Effect of temperature on haematological parameters}

Table 1 represents the changes observed in the blood cell concentrations analyzed in the blood samples stored at different storage systems. For the complete blood count analysis the blood parameters like RBC count, haemoglobin, haematocrit, WBC, MCV, MCHC, RDW were analyzed ${ }^{9}$. It was observed 


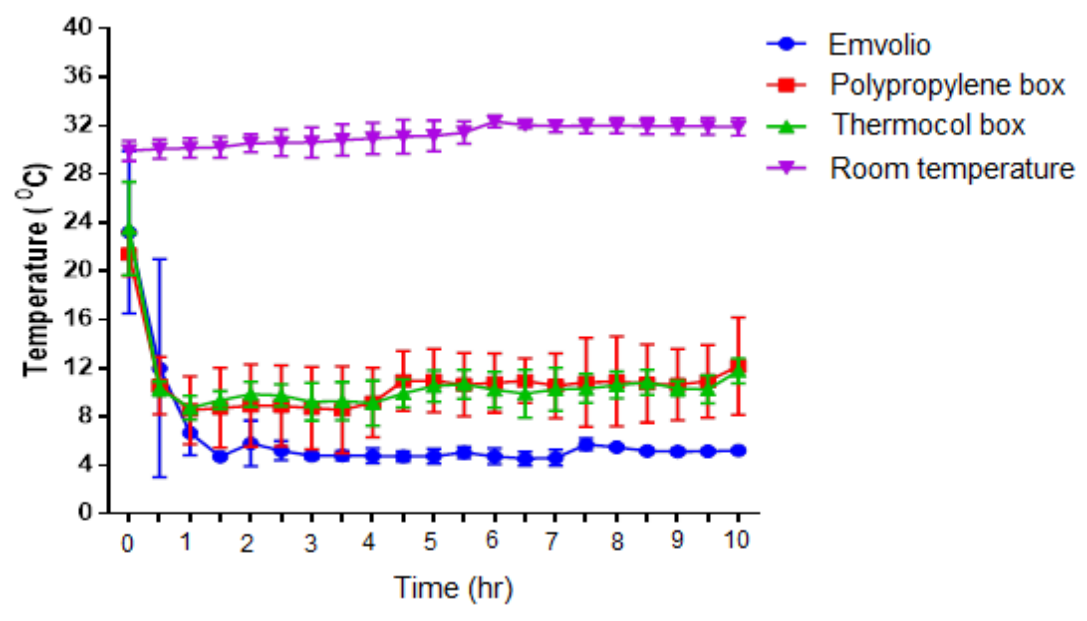

Figure 4. Graph of inner temperature vs time stating the different cooling systems, namely Emvolio, polypropylene box, thermocol box and room temperature.

that at 6 hrs, RBC, haemoglobin and haematocrit values in the samples showed significant differences compared to $0 \mathrm{hrs}$. But WBC, MCV, MCHC and RDW did not produce any statistical changes compared to $6 \mathrm{hrs}$. The samples stored in the polypropylene box showed significant differences in the RBC and haemoglobin after $3 \mathrm{hrs}$ and $6 \mathrm{hrs}$ of storage. There was no significant change in WBC, MCV, MCHC and RDW during the observed duration. The samples stored in gel pad aided cooling in thermocol box showed a significant difference in the RBC after $3 \mathrm{hrs}$ and $6 \mathrm{hrs}$ of the sample storage (Table 1). The samples stored at room temperature showed a significant increase in the RBC count, haematocrit after $3 \mathrm{hrs}$ of storage, and a significant increase in $\mathrm{RBC}$, haemoglobin, haematocrit, and MCV level 6 hrs after the storage. This signifies the effect of the storage temperature on the blood cell count.

\section{Effect of temperature on blood biochemistry}

Among the estimated serum enzymatic parameters, only three parameters, namely alkaline phosphatase, total protein, and albumin, significantly varied with temperature increase. The serum samples stored at room temperature had increased alkaline phosphatase, total protein, and albumin after $6 \mathrm{hrs}$ of collection compared to the $0 \mathrm{hr}$ reading. However, no significant difference was observed in other estimated serum parameters during the observed duration. Serum alkaline phosphatase and total protein were significantly high in samples stored in thermocol box for $6 \mathrm{hrs}$. A significant change in the total protein was observed in the serum stored in thermocol box after 3 hrs. In contrast, other parameters had no significant changes during the storage condition. The serum stored in polypropylene box showed a significantly higher alkaline phosphatase and albumin after a $6 \mathrm{hr}$ duration (Table 2). The samples stored in Emvolio with well-maintained temperature showed fewer fluctuations in the serum parameters. However, a significant change in the alkaline phosphatase was observed and the device was able to maintain a stable enzyme concentration in the stored samples for about $6 \mathrm{hrs}$.

\section{Effect of temperature on tissue biochemistry}

The liver samples stored in the different storage boxes were homogenized and used to estimate the markers like SOD, GSH and catalase. There were no significant differences in liver catalase and GSH when stored in Emvolio for $6 \mathrm{hrs}$. In contrast, SOD had a few fluctuations. The samples stored in polypropylene boxes showed a significant difference in SOD after $3 \mathrm{hrs}$ and $6 \mathrm{hrs}$ of storage. A significantly higher SOD was observed in the samples stored in the thermocol box after $3 \mathrm{hrs}$ and $6 \mathrm{hrs}$, and GSH and catalase after 6 hrs of storage. Samples kept at room temperature showed a significant increase in the SOD level after $3 \mathrm{hrs}$ and $6 \mathrm{hrs}$; catalase after $6 \mathrm{hrs}$ of storage (Table 3).

\section{Discussion}

Emvolio is a precision refrigeration system with an inbuilt internet-of-things (IoT) element that aids in remote-monitoring of vital statistics such as adherence to $2-8^{\circ} \mathrm{C}$. The study conducted aimed to evaluate Emvolio for its efficacy as a biological carrier. The data was compared against the conventionally used non-medical biological carriers, such as thermocol boxes and polypropylene boxes filled with gel-pads. Room temperature was kept as the control group for our data analysis. The temperature recording done for a period of $10 \mathrm{hrs}$ (over seven days) in different cooling systems is represented in Figure 4. Constant temperature within the range of $4-8^{\circ} \mathrm{C}$ was maintained only in the Emvolio cooling system compared to other systems. Both gel-based cooling system in the thermocol box and polypropylene box did not maintain the steady temperature in the $4-8^{\circ} \mathrm{C}$ range, and fluctuations above $8^{\circ} \mathrm{C}$ were observed during the $10 \mathrm{hrs}$ period. A sharp increase in the temperature from $8^{\circ} \mathrm{C}$ to $10^{\circ} \mathrm{C}$ was noticed in the polypropylene box and thermocol box after the 4 hrs duration.

The serum samples stored at room temperature showed a significant increase in alkaline phosphatase $(\mathrm{p}<0.001)$, total protein $(\mathrm{p}<0.01)$, and albumin $(\mathrm{p}<0.05) 6 \mathrm{hr}$ after the collection. A 


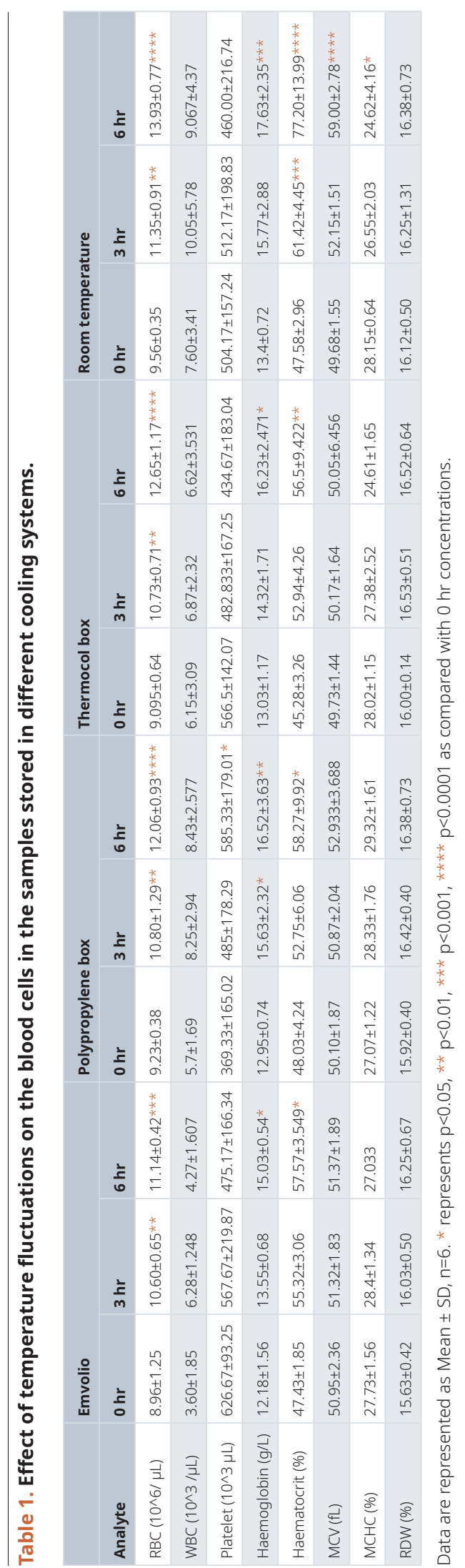




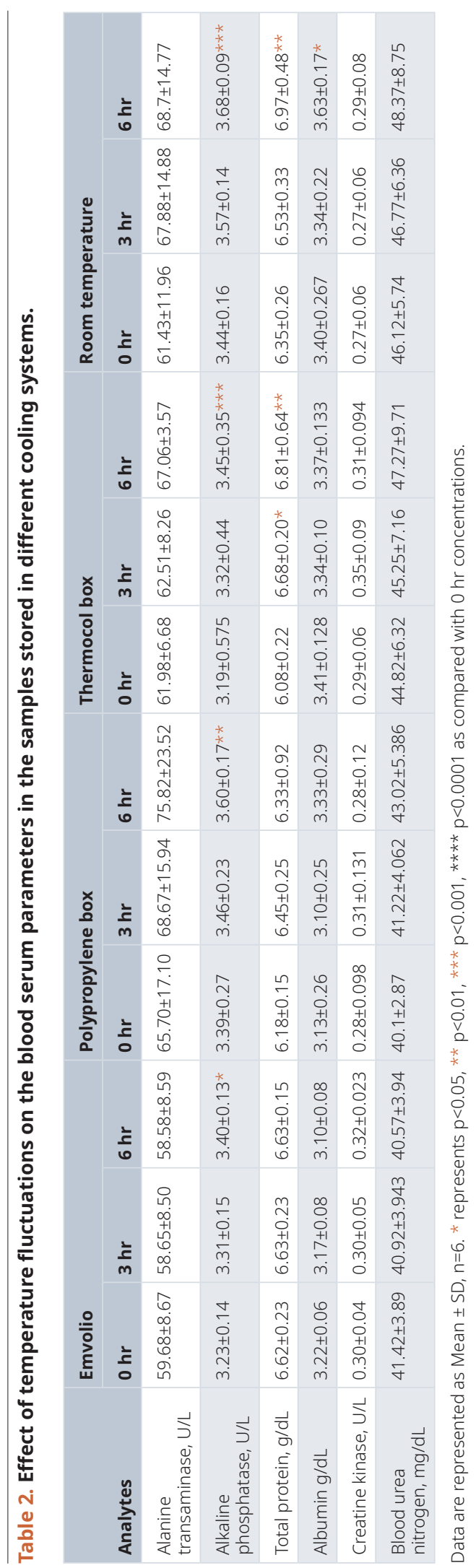




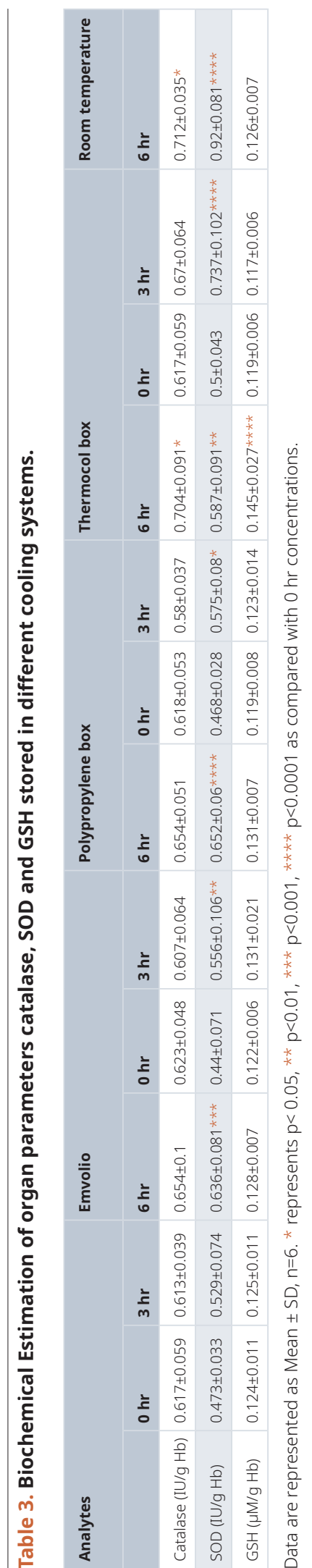


significant change in the total protein $(\mathrm{p}<0.05)$ level was observed in the serum stored in thermocol box after $3 \mathrm{hrs}$. In contrast, other parameters had no significant changes during the storage condition. The serum stored in the polypropylene box showed a significant increase in alkaline phosphatase $(\mathrm{p}<0.01)$ and albumin $(\mathrm{p}<0.05)$ after $6 \mathrm{hrs}$ duration. The samples stored in Emvolio with well-maintained temperature showed fewer serum fluctuations and maintained stable enzyme concentration in the stored samples for $6 \mathrm{hrs}$. The organs stored in the different storage boxes were homogenized and the antioxidant markers, like SOD, GSH and catalase, were estimated. The samples stored in Emvolio showed a significant increase in SOD concentration $(\mathrm{p}<0.001)$ after $6 \mathrm{hrs}$ of storage and no significant changes in the other parameters. The samples stored in polypropylene box showed a significant increase in SOD after $3 \mathrm{hrs}$ $(\mathrm{p}<0.01)$ and $6 \mathrm{hrs}(\mathrm{p}<0.0001)$ of the storage. A significant increase in the SOD was observed in the samples stored in the thermocol box after 3 hrs $(\mathrm{p}<0.05)$ and $6 \mathrm{hrs}(\mathrm{p}<0.01)$, GSH $(\mathrm{p}<0.0001)$ after $6 \mathrm{hrs}$ and catalase $(\mathrm{p}<0.05)$ after the $6 \mathrm{hr}$ duration. Samples kept at room temperature showed a significant increase in the SOD level both after $3 \mathrm{hrs}(\mathrm{p}<0.0001)$ and $6 \mathrm{hrs}(\mathrm{p}<0.0001)$; and catalase $(\mathrm{p}<0.05)$ after $6 \mathrm{hrs}$ of storage. Therefore, it can be inferred that Emvolio maintained a constant temperature of $2-8^{\circ} \mathrm{C}$ throughout the study with minimum fluctuation. Hence, it comes closest to meeting the requirements laid out by the Drug and Cosmetics Act 1940 for a biological carrier. Therefore, Emvolio is a better alternative to maintain the integrity of biological samples.

Gel pads are widely used in the manufacturing and health care industry as coolants. It helps in the maintenance of temperature below the freezing point of the stored sample ${ }^{14}$. The gel pad weighs approximately $500 \mathrm{~g} / \mathrm{pack}$ and contains a liquid cocktail of chemicals that dampen heat conduction of the cold pack, allowing the gel pack to retain the heat, in return keeping its surroundings cool for a more extended period. As per cold chain management guidelines, it is recommended for the use of biologicals. The gel pads need to be frozen $24 \mathrm{hrs}$ before use to act as an aid for the biological carrier. These gel pads are used in traditional transporters such as thermocol boxes and polypropylene boxes. The thermocol boxes are made up of Styrofoam. The heat transfer from the outside environment/ surroundings makes the thermocol boxes an efficient heat insulator. Generally, a thermocol box is loaded with gel packs for the biological transportation technique. This helps retain the coolness for a more extended period. Styrofoam with an extremely low density of $890-910 \mathrm{~kg} / \mathrm{m}^{3}$, when packed in between two plastic walls of polypropylene box, the cooling effect will be better. Further, polypropylene is a low density, chemical resistant, non-corrosive, high temperature resistant biodegradable material. Hence, polypropylene boxes are widely used in the healthcare industry to carry biologicals.

In a developing nation like India, with a high population and a majority residing in rural areas, biological samples are regularly transported over long distances for diagnosis. Research has assessed temperature during vaccine transfers at various levels under the Universal Immunization Program in 21 districts of India - Bihar, Kerala, and Gujarat. A significant episode of sub-zero exposure was reported, and the study concluded that rigorous monitoring of temperature control is essential to ensure vaccines potency and efficacy ${ }^{15}$. Thus, the thought of a technical solution for this is dependent on the availability of continuous electricity for the refrigeration unit to maintain the pre-set temperature and provide a conducive environment to biologicals with special reference to vaccines. However, poor connectivity and erratic power supply had rendered this unviable, especially in the context of rural India ${ }^{16}$.

In Emvolio, the thermoelectric effect is the conversion of voltage difference to temperature difference and vice-versa. In a thermoelectric cooler, when a voltage difference is applied, a temperature difference is observed. The thermoelectric effect in it comprises three different outcomes: Peltier effect, Seebeck effect and Thomson effect. If a direct current is passed through the junction of two differently doped semiconductors, heat flux is generated, called a Peltier effect. This Peltier effect is used for the thermoelectric cooling and heating application ${ }^{17}$. Effectively this device is a heat pump moving heat from one side to the other when a current runs through it. The device has a thermoelectric cooler built around the Peltier chip to achieve cooling. In this system, two different heatsinks are attached to the hot side and the cold side to effectively release and absorb heat. To improve the heat exchange, on the heatsink, fans are mounted. Insulation foam is placed between the heatsinks around the Peltier chip to isolate the hot and cold heat sinks thermostatically. The main advantage of using a thermoelectric cooler over a compressor-based refrigerator is that it has no moving parts or circulating liquids. Further, the thermoelectric cooler is lightweight so makes a very compelling case for use in a portable system $^{18}$, and a digital sensor in the cooling chamber is used for feedback. There are multiple ways to control the temperature of the chamber, Emvolio uses a method called proportional-integral-derivative (PID) controller. PID controller has been an industry standard due to its fast response, accurate setpoint control and fast reaction to disturbance ${ }^{19}$. In most cases, a traditional compressor-based refrigerator uses an on-off based controller, which creates an oscillation in the temperature $^{20}$, which is not suitable for most biological samples. The PID controller consists of three different controllers in itself proportional, integral and differential. The proportional controller gives an output directly proportional to the error in the current temperature $^{21}$. Due to limitations in the PID-controller a steady-state error in temperature may exist, which can be eliminated by an integral controller that sums up all the past errors to give a uniform output. The differential controller predicts the future behaviour of the temperature error and gives the output. Combining all these controllers into a PID controller and a digital sensor helps Emvolio maintain a strict temperature with an error of less than $0.5^{\circ} \mathrm{C}$.

Blood, plasma, and serum analysis are key diagnostic activities in preclinical studies and are also followed in most hospitals to identify health problems ${ }^{22}$. Healthcare has drifted from high facility hospitals, to easy and affordable clinics, to ultimately 
home services with easy accessibility. Hence, it is now crucial that technology and medicine/healthcare goes hand-in-hand for better efficacy and minimizing the chances of error ${ }^{23}$. This could help transform an untenable health system into a tenable one. This will further reduce the chances of personal and environmental error and provide a faster and cheaper method for diagnosing biological samples and organ transportation ${ }^{24}$. To upgrade healthcare with technology, Emvolio can be an aid that can make the patient the point of care. It has the ability to support the diagnostics of one's health at home and transport the sample to their physician at a far-off laboratory. Emvolio can not only fill the gap of the lack of technology access in the rural area, but also can help the healthcare workers to get accurate sample data with minimum damage. Pharma-logistics, as well as academia, have suffered from a lack of reliable last-mile transport ${ }^{25}$. So, technical support is required to aid the healthcare sector in coping with the storage and transportation facility of biologicals. Our study showed that Emvolio could maintain a constant temperature, and the samples stored in Emvolio showed significantly less deflection in the parameters estimated compared to thermocol box and polypropylene box aided with pre-frozen gel pads. The thermocol box and polypropylene box showed deviation from the required temperature range after 0 hrs, and thus, it was observed that the biochemical parameters showed fluctuation by the end of $6 \mathrm{hrs}$. Therefore, there is a critical need to upgrade the transportation and storage facility with appropriate technological support. Emvolio can be adapted for the safe transport of most thermally-sensitive biologicals, and it can be an ideal solution to upgrade the cold chain management system. Thielmann et al., 2019 have carried out a study to verify the quality of vaccine refrigerator management, and they have followed the visual inspections of refrigerators used to store vaccines. As per their study, none of the practises fulfilled the quality criteria of standard practices. Important to them is the non-availability of temperature recording devices and logbooks ${ }^{26}$. Emvolio has inbuilt documentation and temperature recording system and can be used effectively.

Emvolio can be used for samples and specimen transportation for pandemic diseases like COVID-19 and minimize the risk of false negatives arising due to thermally-degraded samples or contamination. Emvolio head cap (lid) seals the device completely. The cold chamber isolates the inside environment from the outer world by using dual-layered stainless steel chambers that maintain a vacuum. So, Emvolio is a much safer option for the transportation of COVID-19 samples with minimal risk of exposure or cross-contamination. The inner metal walls of Emvolio makes it easy for the user to sanitize the device after use, and no additional technical training is required to handle the device. Emvolio is an ideal solution to maintain the integrity of the COVID-19 samples and shows promising potential for effective last-mile transport. The future smart healthcare networks are expected to combine the $5 \mathrm{G}$ and IoT devices and use drones from transportations ${ }^{27,28}$. We propose that Emvolio has the adaptability for these technologies. Further, we propose cold chain management of biologicals with Emvolio, as depicted in Figure 5.
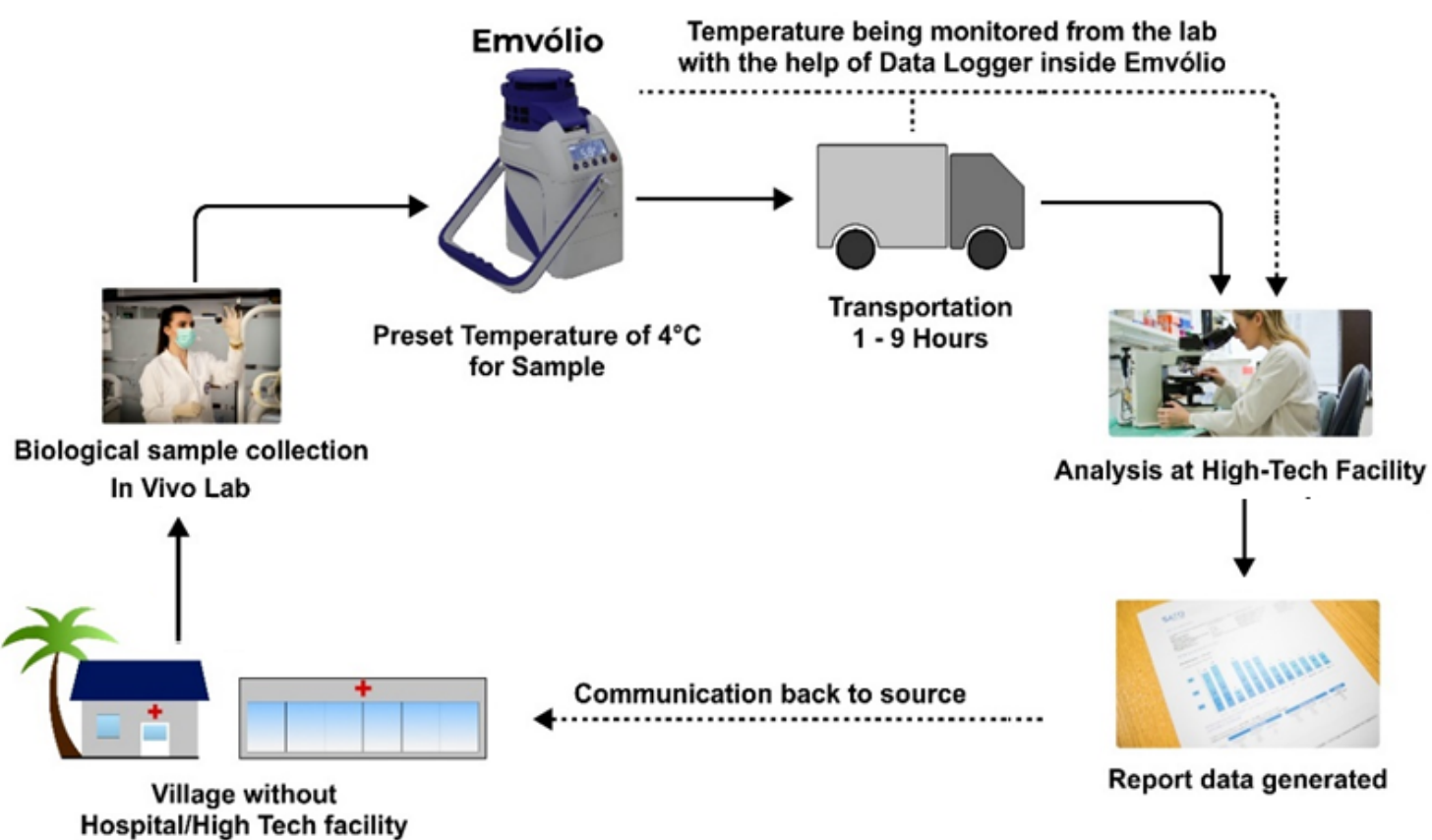

Report data generated

Figure 5. Proposed cold chain management of biologicals with Emvolio. The villages or remote labs do not have direct access to analysis facilities; Emvolio can serve as a supporting aid to transport the sample by maintaining the desired temperature. Such technology will reduce the chances of degradation of the sample and have a higher accuracy rate. 


\section{Conclusion}

Emvolio maintains the constant internal temperature between $2-8^{\circ} \mathrm{C}$, preserving rat blood, serum, and liver for six hours and maintaining biological integrity. Thus, Emvolio can be efficiently used as a biological sample carrier, especially in preclinical studies.

\section{Data availability}

Underlying data

Mendeley Data: 'Effect of temperature on hematological and biochemical parameters when the biological sample from rats kept in room temperature, thermocol, polypropylene box and innovative portable refrigerator' https://doi.org/10.17632/ vgdm3299fp. 2. .

This project contains the following underlying data:

- Temperature effect - Comparison of Biochemical \& Hematological parameter_v2.xlsx (Effect of temperature fluctuations on the haematological parameters such as total RBC, WBC, platelets, and haemoglobin, haematocrit, MCV, MCHC, RDW in the blood samples, serum parameters such as ALT, ALP, total protein, albumin, creatinine kinase, blood urea nitrogen, and biochemical parameters in liver such as catalase, SOD and GSH stored in different cooling systems).

Data are available under the terms of the Creative Commons Attribution 4.0 International license (CC-BY 4.0).

\section{Reporting guidelines}

Mendeley data: ARRIVE checklist for 'Emvolio - A battery operated portable refrigerator preserves biochemical and haematological integrity of biological samples in preclinical studies' https://doi.org/10.17632/vgdm3299fp. .

Data are available under the terms of the Creative Commons Attribution 4.0 International license (CC-BY 4.0).

\section{Acknowledgements}

Authors acknowledge the Blackfrog Technologies Pvt. Ltd, Manipal, Karnataka, India, for providing the product "Emvolio" to conduct the study. Authors also thank Manipal Academy of Higher Education for supporting Open Access funding.
1. Tripathi A, Sathua K, Pachauri V, et al.: Collection, storage, and transportation of samples for offsite analysis. Handbook on Biological Warfare Preparedness. Elsevier; 2020; 133-149. Publisher Full Text

2. Yevdulov O, Yusufov S, Mispakhov I: Device for short-term storage and transportation of biological materials. In: Refrigeration Science and Technology. International Institute of Refrigeration; 2018; 149-54.

3. Maiorino A, Petruzziello F, Aprea C: Refrigerated Transport: State of the Art Technical Issues, Innovations and Challenges for Sustainability. Energies. 2021; 14(21): 7237. Publisher Full Text

4. Vaught JB, Henderson MK: Biological sample collection, processing, storage and information management. IARC Sci Publ. 2011; (163): 23-42. PubMed Abstract

5. Campbell LD, Betsou F, Garcia DL, et al:: Development of the ISBER best practices for repositories: Collection, storage, retrieval and distribution of biological materials for research. Biopreserv Biobank. 2012; 10(2): 232-3. PubMed Abstract | Publisher Full Text

6. Crespi-Lofton J, Skelton JB: The growing role of biologics and biosimilars in the United States: Perspectives from the APhA Biologics and Biosimilars Stakeholder Conference. J Am Pharm Assoc (2003). 2017; 57(5): e15-27. PubMed Abstract | Publisher Full Text

7. Comes T, Bergtora Sandvik K, van de Walle B: Cold chains, interrupted: The use of technology and information for decisions that keep humanitarian vaccines cool. J Humanit Logist Supply Chain Manag. 2018; 8(1): 49-69. Publisher Full Text

8. Das MK: COVID-19 vaccine and the cold chain implications for global adoption. Indian J Public Health. 2021; 65(3): 307-10. PubMed Abstract

9. Maity S, Aakriti J, Manandhar S, et al.: Effect of temperature on hematological and biochemical parameters when the biological sample from rats kept in room temperature, thermocol, polypropylene box and innovative portable refrigerator. Mendeley Data, V2, 2022 http://www.doi.org/10.17632/vgdm3299fp.2

10. Regan RD, Fenyk-Melody JE, Tran SM, et al.: Comparison of Submental Blood Collection with the Retroorbital and Submandibular Methods in Mice (Mus musculus). J Am Assoc Lab Anim Sci. 2016; 55(5): 570-6. PubMed Abstract | Free Full Text

11. Nagamma T, Konuri A, Nayak CD, et al.: Dose-dependent effects of fenugreek seed extract on the biochemical and haematological parameters in highfat diet-fed rats. J Taibah Univ Med Sci. 2019; 14(4): 383-9.

PubMed Abstract | Publisher Full Text | Free Full Text

12. Leoni S, Tovoli F, Napoli L, et al.: Current guidelines for the management of non-alcoholic fatty liver disease: A systematic review with comparative analysis. World J Gastroenterol. 2018; 24(30): 3361-73. PubMed Abstract | Publisher Full Text | Free Full Text

13. Bunney PE, Zink AN, Holm AA, et al.: Orexin activation counteracts decreases in nonexercise activity thermogenesis (NEAT) caused by high-fat diet. Physiol Behav. 2017; 176(5): 139-48.

PubMed Abstract | Publisher Full Text | Free Full Text

14. Breslin M, Lam P, Murrell GA: Acute effects of cold therapy on knee skin surface temperature: gel pack versus ice bag. BMJ Open Sport Exerc Med. 2015; 1(1): e000037.

PubMed Abstract | Publisher Full Text | Free Full Text

15. Das MK, Arora NK, Mathew T, et al.: Temperature integrity and exposure of vaccines to suboptimal temperatures in cold chain devices at different levels in three states of India. Trop Dis Travel Med Vaccines. 2020; 6(1): 8 PubMed Abstract | Publisher Full Text | Free Full Text

16. Mohan $P$, Kumar R: Strengthening primary care in rural India: Lessons from Indian and global evidence and experience.J Family Med Prim Care. 2019; 8(7): 2169-72.

PubMed Abstract | Publisher Full Text | Free Full Text

17. Wang J, Wang JB, Long ZY, et al.: Design and application of a cooling device based on peltier effect coupled with electrohydrodynamics. Int J Therm Sci. 2021; 162: 106761 Publisher Full Text

18. Garrido J, Manzanares JA: Heat and work fluxes in thermoelectric coolers. Therm Sci Eng Prog. 2021; 22: 100817. Publisher Full Text

19. Hamid NHA, Kamal MM, Yahaya FH: Application of PID controller in controlling refrigerator temperature. In: 2009 5th International Colloquium on Signal Processing \& Its Applications. Kuala Lumpur: IEEE; 2009; 378-84. Publisher Full Text

20. Yalawar MS, Challa MK, Yalawar S: Enhancing the Smart Refrigerator using the IoT. Int J Recent Technol Eng. 2019; 8(2S8): 1734-40. Publisher Full Text

21. Okochi GS, Yao Y: A review of recent developments and technological advancements of variable-air-volume (VAV) air-conditioning systems. 
Renew Sustain Energy Rev. 2016; 59: 784-817. Publisher Full Text

22. Gillio-Meina C, Cepinskas G, Cecchini EL, et al.: Translational research in pediatrics II: blood collection, processing, shipping, and storage. Pediatrics. 2013; 131(4): 754-66.

PubMed Abstract | Publisher Full Text

23. Dyb K, Berntsen GR, Kvam L: Adopt, adapt, or abandon technologysupported person-centred care initiatives: healthcare providers' beliefs matter. BMC Health Serv Res. 2021; 21(1): 240. PubMed Abstract | Publisher Full Text | Free Full Text

24. Kara-Junior N: Technology, teaching, and the future of ophthalmology and the ophthalmologist. Arq Bras Oftalmol. 2018; 81(3): V-VI. PubMed Abstract | Publisher Full Text

25. Argiyantari B, Simatupang TM, Hasan Basri M: Pharmaceutical supply chain transformation through application of the Lean principle: A literature review. J Ind Eng Manag. 2020; 13(3): 475.

Publisher Full Text

26. Thielmann A, Puth MT, Weltermann B: Visual inspection of vaccine storage conditions in general practices: A study of 75 vaccine refrigerators. Pakhare AP, editor. PLoS One. 2019; 14(12): e0225764.

PubMed Abstract | Publisher Full Text | Free Full Text

27. Ahad A, Tahir M, Yau KLA: 5G-Based Smart Healthcare Network: Architecture, Taxonomy, Challenges and Future Research Directions. IEEE Access. 2019; 7: 100747-62. Publisher Full Text

28. Zailani MAH, Sabudin RZAR, Rahman RA, et al.: Drone for medical products transportation in maternal healthcare: A systematic review and framework for future research. Medicine (Baltimore). 2020; 99(36): e21967. PubMed Abstract | Publisher Full Text | Free Full Text 


\section{Open Peer Review}

\section{Current Peer Review Status: ?}

\section{Version 1}

Reviewer Report 06 October 2022

https://doi.org/10.5256/f1000research.120598.r150286

(C) 2022 Aprea C. This is an open access peer review report distributed under the terms of the Creative Commons Attribution License, which permits unrestricted use, distribution, and reproduction in any medium, provided the original work is properly cited.

\section{Ciro Aprea}

Department of Industrial Engineering, University of Salerno, Salerno, Italy

The title of the paper is "A battery operated portable refrigerator preserves biochemical and haematological integrity of biological samples in preclinical studies". In this paper the authors present a refrigerated system equipped with a Peltier module finalized to vaccine preservation in the range $2^{\circ} \mathrm{C}-8^{\circ} \mathrm{C}$. The aim of their study is to obtain a system capable of maintaining the vaccine storage temperature when the system is picked up from a refrigerated space where it has been located to reach the correct storage temperature. The Peltier module can contribute to maintain the "cold chain".

The device presented is interesting but some aspects have to be evidenced.

1. Which is the autonomy of the battery of the refrigerator when the ambient temperature is of $32^{\circ} \mathrm{C}$ ?

2. And the autonomy of the battery when the refrigerator is opened and closed every hour for thirty seconds (simulation for withdraw the vaccine inside)

3. In this last case which is the time necessary for restore the correct temperature?

4. In this last case which is the maximum temperature reached with reference to the temperature set-point?

5. The temperature of $2^{\circ} \mathrm{C}-8^{\circ} \mathrm{C}$ are useful only for some vaccines. For Covid-19 the correct conservation temperature of some vaccines are also $-20^{\circ} \mathrm{C}$ (Moderna for example).

Is the work clearly and accurately presented and does it cite the current literature? Yes

Is the study design appropriate and is the work technically sound? 
Are sufficient details of methods and analysis provided to allow replication by others? Yes

If applicable, is the statistical analysis and its interpretation appropriate?

Not applicable

Are all the source data underlying the results available to ensure full reproducibility?

Yes

Are the conclusions drawn adequately supported by the results?

No

Competing Interests: No competing interests were disclosed.

Reviewer Expertise: Applied thermodynamics, Refrigeration

I confirm that I have read this submission and believe that I have an appropriate level of expertise to confirm that it is of an acceptable scientific standard, however I have significant reservations, as outlined above.

Author Response 26 Oct 2022

Yogendra Nayak, Manipal Academy of Higher Education, Manipal, India

Dear Ciro Aprea,

We thank for your valuable questions and suggestions. Authors are obliged to the reviewer comments. Followings are the answers to your comments.

Q1. Which is the autonomy of the battery of the refrigerator when the ambient temperature is of $32^{\circ} \mathrm{C}$ ?

Response: The product (Emvolio) has been tested and successfully passed the stringent WHO/PQS/E003/TS01.1 standard for a transportable, powered vaccine appliance. One of the primary requirements for the test is the autonomy of the battery for a minimum of 12 hours at extreme heat of $43^{\circ} \mathrm{C}$ ambient temperature. Please see the archived test reports at an independent WHO-accredited test facility wherein Emvolio ran for 13+ hours.

Q2. And the autonomy of the battery when the refrigerator is opened and closed every hour for thirty seconds (simulation for withdraw the vaccine inside)

Response: The autonomy during temperature excursions due to human interference is also captured in the above-mentioned report.

Q3. In this last case which is the time necessary for restore the correct temperature?

Response: We have conducted internal testing to determine the rate of temperature 
excursions and cool-down period due to human interference, i.e. opening/closing the lid. The results have also been contrasted against routinely used ice-based refrigeration systems. This report is also archived in a similar manner.

Q4. In this last case which is the maximum temperature reached with reference to the temperature set-point?

Response: The maximum temperature reached typically is dependent on the ambient temperature. We conducted our interference testing at $34^{\circ} \mathrm{C}$, wherein the maximum temperature inside the cold chamber was between $9-11^{\circ} \mathrm{C}$.

Q5. The temperature of $2^{\circ} \mathrm{C}-8^{\circ} \mathrm{C}$ are useful only for some vaccines. For Covid-19 the correct conservation temperature of some vaccines are also $-20^{\circ} \mathrm{C}$ (Moderna for example).

Response: There is a popular misconception that since the Moderna vaccine requires $-20^{\circ} \mathrm{C}$ and the Pfizer vaccine requires an even colder $-80^{\circ} \mathrm{C}$, it could be incompatible with typical vaccine carriers. These ultra-cold temperatures are meant for long-term storage and transport of the vaccines in the early parts of the supply chain. Incidentally, the Moderna vaccine is thermostable at $2-8^{\circ} \mathrm{C}$ up to 30 days, and the Pfizer vaccine is thermostable at 2$8^{\circ} \mathrm{C}$ up to 7 days as per the regulator's data (For reference, click here for the report). This implies that regardless of their strict storage requirements, the last-mile transport will always be dependent on a $2-8^{\circ} \mathrm{C}$ cold chain, which Emvolio fulfils. Any vaccine, regardless of extreme storage temperatures, must be thawed before being administered to a recipient to avoid shock/injury. Once thawed, the vaccines cannot be refrozen again, which underlines the need for precision temperature control that other ice-based coolers fall short in.

Further, we thank the reviewer for the input which made the reader a clear idea about the paper.

Authors are obliged to the reviewer comments

Competing Interests: Authors declares that there is no competing interest in publishing this response to reviewer comments. 
The benefits of publishing with F1000Research:

- Your article is published within days, with no editorial bias

- You can publish traditional articles, null/negative results, case reports, data notes and more

- The peer review process is transparent and collaborative

- Your article is indexed in PubMed after passing peer review

- Dedicated customer support at every stage

For pre-submission enquiries, contact research@f1000.com 